\title{
Gay Male Football Fans' Experiences: Authenticity, Belonging and Conditional Acceptance
}

\author{
Sociology \\ (accepted $12^{\text {th }}$ January 2021) \\ Rory Magrath \\ Solent University, UK
}

\begin{abstract}
The relationship between English football and homosexuality has changed significantly in recent years. However, research examining this area of study has been predominantly focused on the attitudes of ostensibly heterosexual men. By drawing on semi-structured interviews with 35 'out' gay male fans, this article is the first to focus explicitly on LGBT fans' sense of place in English football. Contrary to previous research, these gay male fans represent 'authentic' notions of fandom through their passion for football and respective clubs. The recent emergence of LGBT Fan Groups has provided sexual minority fans increased visibility, and a sense of belonging and community. Finally, despite ongoing concerns about football stadia's hypermasculine and heteronormative environment, these fans believe that they have become an increasingly inclusive space. Accordingly, this article demonstrates that sexual minority fans are central to English football and argues that future research must acknowledge their increased prevalence.
\end{abstract}

Keywords: Fandom; Football; Homophobia; LGBT; Sexuality; Sport 


\section{Introduction}

English men's professional football has undergone considerable structural and social change over the past three decades (King, 2002). The inception of the English Premier League (EPL) in the early-1990s, and its subsequent development into the world's most popular football league (Millward, 2011), is at least partly responsible for the notable expansion of both domestic and global fan cultures of the English game (Crawford, 2004; Giulianotti, 2002; Pearson, 2012). English football's ongoing commitment to challenging discrimination has also influenced a diversification of fandom inside English stadia. Indeed, research has sought to address the experiences of traditionally marginalised fans, including female fans of men's football (Pope, 2017), Black, Asian and Minority Ethnic (BAME) fans (Lawrence and Davis, 2018) and disabled fans (García et al., 2016).

The emergence and increase of LGBT Fan Groups in English football in recent years - at the time of writing almost half of the 92 professional English clubs have a group aligned to them - has played an important role in providing sexual minority fans with a sense of community and belonging. There is, for example, a growing body of research documenting inclusive attitudes towards homosexuality among ostensibly heterosexual fans and athletes (Cashmore and Cleland, 2012; Cleland, 2015; Cleland et al., 2018; Magrath, 2017, 2018). Curiously, however, the experiences of lesbian, gay, bisexual and/or transgender (LGBT) fans remains entirely absent from existing work on sports fandom. Given football's centrality in British culture, hearing LGBT voices is an important component of sports research particularly in the broader context of increased cultural acceptance in recent years (McCormack, 2012).

Addressing the absence of LGBT fans in the literature, this article draws upon semistructured interviews with 35 'out' gay male ${ }^{i}$ fans of various English professional clubs to develop an understanding of their sense of place in football. Findings indicate that, contrary 
to previous research (e.g., Jones, 2008), these gay men represent 'authentic' notions of fandom - largely evident through the centrality of football in the construction of their identities. Moreover, the emergence of LGBT Fan Groups are also shown to be important in providing sexual minority fans with visibility, belonging and a sense of community in an environment from which they have previously been excluded. Finally, I show that, despite ongoing concerns, English football is now an overwhelmingly inclusive environment - best evidenced by the growing number of LGBT fans attending matches and the decline of discriminatory chanting.

This research therefore advances existing narratives regarding understanding of English football's liberalising attitudes toward homosexuality, while simultaneously recommending caution in light of its persistent and ongoing heteronormative culture. It also builds on other recent research in providing a critique of existing frameworks for football fandom and argues that LGBT fans - alongside other traditionally marginalised fan groups should be incorporated into contemporary redevelopments of fan conceptualisations. Finally, it extends these debates about fandom to broader sociological questions around the development of community and belonging in contemporary society (Neal et al., 2019). With gay men demonstrating a sense of belonging and community in the traditionally hypermasculine and heteronormative culture of football, this research suggests a renewed focus in the sociology of sport and leisure to focus on practices of inclusion and belonging in sport, as well as social exclusion.

\section{Conceptualising English Football Fandom}

English football culture has traditionally been dominated by heterosexual, white, workingclass men (Goldblatt, 2014). In the 1980s, English football was characterised by antisocial behaviour by fans. The severity of these issues even resulted in warnings from the prime 
minister, Margaret Thatcher, that English football could be banned, and it was described by the Sunday Times as a 'slum sport played in slum stadiums, increasingly watched by slum people' (cited in King, 2002: 93). Fandom at the time was associated with 'drunken destructiveness [and] a rampage of uncontrollable masculine passion' (Jensen, 1992: 15). Against this backdrop, match attendance reached a new post-war low by the end of the decade (Goldblatt, 2014).

The creation of the EPL in 1992 was important for this change of ethos, as it facilitated greater processes of commercialisation and commodification (Giulianotti, 2002; King, 1997, 2002; Millward, 2011; Pearson, 2012). Backed by Sky's television money and the transformation of stadia into all-seater, family-friendly arenas, clubs endeavoured to attract more affluent audiences - 'customers', rather than fans - to football matches (King, 2002). The attempted bourgeoisification of fandom was, largely, clubs' efforts to nullify the damage caused to English football by the antisocial behaviours so prevalent in the previous decade. In attempting to diversify fandom, however, this both alienated and marginalised football's 'traditional' working-class fans. Evidencing this, King's $(1997,2002)$ seminal research on the Manchester United 'lad' showed how, despite identifying as some of the club's most loyal fans, they became increasingly excluded and alienated by the club's attempts to diversify its fanbase.

The contemporary diversification of fandom, coupled with the EPL's multiple global successes (Millward, 2011), has led to a proliferation of 'new' fan cultures. Conceptualising these changes, Giulianotti's (2002) taxonomy of spectator identities in football (see Figure 1) has emerged as the most comprehensive theoretical model of fandom. Here, Giulianotti (2002) argues that spectators' consumption of football can be categorised by two key factors: loyalty to club and how fandom relates to social identity. These factors intersect to form a two-by-two grid and four quadrants of fandom: 'supporters', 'fans', 'followers' and 
'flâneurs'. According to Giulianotti (2002), supporters and followers tend to have affiliation to a club based on location and loyalty, but supporters typically have more intense identification with the club than followers. Fans and flâneurs' relationship with a club is more determined by consumption of club products and merchandise, with fans having a closer identification with a club than flâneurs.

Insert Fig. 1.

The influence of Giulianotti's taxonomy is evident through the broad range of research across various sporting contexts which draws upon its central themes (e.g. Kossakowski, 2017; Leonard, 2005; Millward, 2011). But despite its focus on the divergence of contemporary fandom, Giulianotti's taxonomy does not consider diversification beyond white, heterosexual male spectators and so does not account for the barriers which underrepresented spectators may need to overcome to attend matches. Recent years have seen the diversification of English football fandom (e.g. García et al., 2016; Pope, 2017; Pfister and Pope, 2017; Lawrence and Davis, 2018), although LGBT fans' voices remain largely excluded from this body of work.

\section{English Football, Masculinity and Homophobia}

English football's gendered history can be traced to the mid-19 ${ }^{\text {th }}$ century (Goldblatt, 2014). Against the backdrop of a fast-changing society - largely influenced by industrialisation (Riess, 1995) - representatives from several clubs met to agree a unified set of laws for English football (Taylor, 2008). The formal establishment of football also had broader cultural significance. Indeed, because of emergent concerns about homosexuality among adolescent boys, participation in football - and other teamsports - provided them with an 
opportunity for them to 'align their gendered behaviors with idealized and narrow definitions of masculinity' (McCormack and Anderson, 2014: 114). Thus, by supressing pain, concealing same-sex desire and behaviours and committing acts of violence against oneself and others, boys were able to avoid the 'risk' of homosexuality, while simultaneously preparing them for labour-intensive factory work and participation in the military (Raphael, 1988).

In this context, English football developed a hypermasculine culture; one dominated by a thuggish and violent form of masculinity, both on and off the pitch (Magrath, 2018). Given this hypermasculine environment evident throughout English football's history, any alternative sexuality has been emphatically and explicitly rejected. In this context, gay sports clubs emerged to offer sexual minorities a sense of liberation - what Elling et al. (2003: 452) call 'queer resistance' - away from mainstream sport, which was, at this time, a toxic environment for sexual minorities (Curry, 1991; Hekma, 1998; Pronger, 1990). Thus, it was in these segregated spaces that gay men were able to disrupt those who prejudice gay masculinities as weaker and less competitive and, in turn, contrary to mainstream football's masculine ideals.

At professional level, this toxic environment was best evidenced by the example of Justin Fashanu. Fashanu became the world's first out male professional footballer when he came out via The Sun in 1990 (Cleland, 2014). Ultimately, he suffered vilification and rejection from the football industry and, following allegations of sexual assault in the US, took his own life in 1998 (Gaston, Magrath and Anderson, 2018). His experiences reflected broader cultural attitudes towards gay men at the time he came out. Largely facilitated by HIV/AIDS - which was prevalent among gay men - homophobic attitudes in the UK increased throughout most of the 1980s. The British Social Attitudes Survey showed that, in $1983,62 \%$ of the UK population believed that same-sex sex between consenting adults was 
'always wrong' or 'mostly wrong'; by 1987, this figure had increased to $75 \%$. However, this marked the highest levels of homophobic recorded by this survey, with a sustained decline ever since (Watt and Elliot, 2019). Indeed, the 2019 British Social Attitudes Survey showed that only $16 \%$ of those sampled believed same-sex sex to be 'always wrong' or 'mostly wrong'.

Despite frequent claims to the contrary (e.g., Goldring, 2018), British sport has reflected broader cultural trends of inclusivity towards sexual minorities (Anderson et al., 2016). In football, this is most notable in Cashmore and Cleland's (2012) survey of fans, which found that $93 \%$ of 3500 respondents were supportive of the hypothetical notion of an out gay male professional footballer. These fans believed that a player's on-field performance was the only significant factor on which they should be judged; many also resented being blamed for the lack of out gay players, and almost half the sample believed that clubs and agents were responsible. Similarly, Magrath's (2018) interview-based research found a nearunanimous acceptance of gay players in football while also critiquing previous research which claims homophobic chanting - or 'homosexually-themed chanting' - is endemic inside English stadia. Nevertheless, Pearson (2012) argues that use of this language makes football an uncomfortable space for gay fans.

Netnographic research on football fans has also documented widespread support for homosexuality in English football. Cleland's (2015) examination of homosexuality on fan forums found broadly positive discussions, as well as a rejection of posts containing homophobic sentiment. Similarly, Cleland et al.’s (2018: 105) analysis of forums' discussions of German player Thomas Hitzlsperger's coming out found that fans are 'becoming less obsessed by historic definitions of masculinity and, instead, are using the Internet to present more inclusive forms of masculinity and sexuality'. 


\section{LGBT Fan Groups and the Sociology of Community}

Partly responsible for English football's growing acceptance of sexual minorities is the influence of LGBT Fan Groups. Since a group of LGBT Arsenal fans founded the Gay Gooners in 2013, these groups have emerged in significant numbers. Indeed, at the time of writing, 44 of the 92 English professional clubs competing in either the EPL (20 clubs) or English Football League (EFL) (72 clubs) have an officially sanctioned LGBT Fan Group, meaning that the group is officially recognised and endorsed as a subsidiary of the club in question. Perhaps reflecting the league's overall popularity, this figure also includes 17 of the EPL clubs at the start of the 2020-21 English football season.

The general purpose of LGBT Fan Groups - and the overarching organisation to which these groups are affiliated, Pride in Football - is to provide a counterspace to English football's traditionally hypermasculine and heteronormative atmosphere, and thus provide LGBT fans with an inclusive and safe space. In some cases, they work with clubs to improve LGBT fans' general experiences and, in some cases, assist the club with steward training and incident reporting (Pride in Football, 2020). Perhaps more importantly, they also provide greater visibility and a sense of belonging and community for sexual minority fans in an environment from which they have traditionally been excluded. Accordingly, comparisons can be made with recent (re)framing on the notion of 'community' (see Neal et al., 2019). In this context, it can be argued that LGBT Fan Groups act as key spaces for sexual minorities fans' increasing sense of belonging in mainstream sport.

This notion of belonging, and the active development of community, is gaining increased attention in sociological research (Neal et al., 2019). In her ethnographic study of a ten-pin bowling alley in London, Jackson (2020) highlights the processual and interactional nature of developing communities within sporting leagues, in contrast to older work - such as Putnam's (2000) seminal study which sees community as a 'noun that is achieved through a 
narrowly defined set of organised practices' (Jackson, 2020: 519). Jackson sees participation in a bowling league as the opportunity to develop community through practices of belonging and becoming. In this way, there has been a turn to seeing leisure-time sport through a lens of facilitating friendship and community. LGBT Fan Groups may well be another way of developing community, yet they tend to be viewed primarily as a protection from prejudice and discrimination, and community-building aspects are downplayed.

\section{Methods}

\section{Participants}

Part of a broader project on the experiences and perspectives of LGBT football fans, this article draws on in-depth semi-structured interviews with 35 gay male fans of various English professional football clubs. Given the gender differences in the history and narratives of football fandom, the heterogeneity of LGBT communities, and that sexual minorities face different social exclusions (Formby, 2017), I focus on gay men's experiences in this article and explore lesbian, bisexual and transgender fans' perspectives elsewhere.

Participants in this research typically reflected the traditional demographic of English football stadia (Goldblatt, 2014); all but one was white (the exception being Asian Indian) and aged between 19 and 67. All were working-class or lower middle-class, as determined by participants' occupation and/or educational status. Participants identified as 'fans' of 23 separate clubs currently competing in either the EPL or EFL, and 26 held season-tickets for their respective clubs. Although there was no strategy for recruiting fans from clubs competing at any particular level of English football, two-thirds of the sample supported clubs who, at the time of writing, competed in the EPL. Accordingly, given the qualitative nature of this research, there may be discrepancies between the experiences of fans from one of the 20 EPL clubs and those who represent one of the 72 EFL clubs. This could, perhaps, be 
attributable to the elevated levels of what Cleland and Cashmore (2016) refer to as the 'sanitisation' of fandom at the top level of English professional football caused by more intense processes of commercialisation (David and Millward, 2012).

All participants in this research were recruited through social media. The emergence of the Internet in recent years has enabled greater opportunity for researchers to engage with online cultures across multiple platforms (Cleland et al., 2020). It is also an important site for historically marginalised groups to create various social networks (Mehra et al., 2004). The proliferation of social media in particular has provided researchers with a rich data source into new, previously under-researched areas of study and groups of people (Gellinas et al., 2017). It is also a valuable resource through which contact can be made with potential research participants - especially those who have been historically hard to locate (Poynter, 2010). Despite these benefits, however, it must be recognised that social media - in this case, Twitter - is not reflective of wider society (Sparkes and Smith, 2014).

Given that Twitter is the most popular outlet through which LGBT football fans network ${ }^{\mathrm{ii}}$, most participants were located through this medium. Through the creation of a new Twitter account - @LGBTFansProject - an advert was posted with the overall aims of the research. Given the unique nature of the project, this was then 'shared' almost 100 times by various key organisations and key figures in sports media. While the project as a whole underwent two ${ }^{\mathrm{iii}}$ waves of participant recruitment, with two eligibility criteria, only the first was relevant for the gay male fans included as part of this research. This eligibility criteria included: self-identification as lesbian, gay, bisexual and/or transgender; those who supported a team who competed in the EPL or EFL; and those who were either season-ticketholders or attended at least $50 \%$ of their team's matches, either at 'home', 'away' or a combination of both. Adopting this approach permitted, to some degree, the recruitment of participants who 
Giulianotti (2002: 31) might refer to as 'traditional' and 'hot' (i.e. fans with a longer and more intense relationship with their respective club).

\section{Procedures}

Participants represented a range of different clubs from across England. To ensure consistency of approach throughout the project, as well as avoiding the risk of excluding fans located furthest away, all interviews were conducted on the telephone. They ranged from between 45 minutes and 2 hours, averaging approximately an hour. Data was collected over an eight-month period, between July 2018 and March 2019. Prior to interview, participants were emailed documentation reiterating the overall aims of the research, and researcher contact details should they have had any queries or wanted to remain informed about the progress of the research project. Each participant also electronically signed a consent form. Ethical approval was granted by my institution prior to data collection, and all ethical guidelines of the British Sociological Association (BSA) were followed. Confidentiality and anonymity were assured throughout the research process, as evidenced by the use of pseudonyms. In some cases, this also included ensuring that participants could not be identified in their role as a founder or co-founder of a professional club's LGBT Fan Group; in these cases, reference to their respective club has been removed.

Interviews began with a general discussion of topical issues in football, such as the 2018 World Cup (which was in progress at the start of data collection), start of the 2019-20 football season and use of the new Video Assistant Referee (VAR) in various tournaments; such conversations have previously been documented as an effective way to develop rapport in sports-based research (Magrath, 2017). The aims of the project were then outlined to participants, before interviews then focused on four central themes: attendance at English 
football matches; stadium climate for LGBT fans; chanting and language in football; and the role of governing bodies and clubs in tackling discrimination.

Interviews were transcribed and coded upon completion. Because this was the first scholarly research dedicated to the experiences of LGBT football fans, an inductive framework was adopted with a thematic analysis (Charmaz, 2014) employed when analysing results. To avoid a diluted and confused application to thematic analysis, Braun et al.'s (2016) guidance list was followed throughout the data analysis process. This included a thorough and comprehensive approach to coding, as well as a detailed interpretation of analytic claims. Accordingly, this ensured a 'rigorous, deliberative process for doing thematic analysis, that keeps “quality” as a foregrounded concern' (Braun et al., 2016: 202).

\section{Results}

The following sections outline the experiences and perspectives of gay male football fans. First, I discuss these fans' route into fandom, before showing that their passion for football is indicative of what Giulianotti (2002) refers to as 'traditional' and 'hot' forms of spectatorship. I then document the emergence of LGBT Fan Groups as important for providing sexual minority fans with a sense of belonging and community in the hypermasculine environment of football. Third, I explore how these fans describe football as being an 'unwelcome' environment for sexual minority fans, with many also modifying their behaviours to avoid suspicion of their sexuality. Finally, I show that, despite their concerns, almost every participant believed English football had become more accepting of homosexuality in recent years (Cashmore and Cleland, 2012; Cleland, 2015; Cleland et al., 2018; Magrath, 2017, 2018) — as evidenced by their routine acceptance, and decline of discriminatory chanting. 


\section{Gay Men and Authentic Fandom}

Despite the 'authentic' football fan being seen as heterosexual, white, working-class men (e.g. King, 1997, 2002; Pearson, 2012), the gay male fans in this research counter previous narratives of inauthenticity (Jones, 2008). Indeed, as evidenced by general conversations at the start of interviews, football was a central component of these fans' identities. Congruent with research on heterosexual male fans (King, 1997), each of them spoke passionately about their personal and historical relationships with football - and the club they support.

Additionally, approximately three-quarters of participants hold season-tickets for their respective clubs, and around half attend at least $50 \%$ of away matches.

Fans' route into fandom was mostly attributable to notable sporting events and players or being introduced to football from a young age. Jason, a Bournemouth fan studying Communication and Media at university, said that he became 'hooked' on football as a youngster after the club won the Division Three play-offs in 2003: 'When we [Bournemouth] won in Cardiff, that was it...I've loved it ever since'. Similarly, Gordon, a retired Tottenham Hotspur fan, referred to the club's successful past as the precursor to his love for football: 'I grew up watching great players at a time when we won things regularly...I've been fixated with the club ever since'. Noel, a West Ham United fan and season-ticketholder, acknowledged his parents' role in his interest in football: 'They [parents] took me to the Boleyn Ground when I was a kid and I've been obsessed with football - and West Ham ever since. It's just my life'.

Approximately two-thirds of the fans in this research were introduced to football a young age by family members and, in many cases, still attend matches with them. For example, Elliott, a Leicester City fan, said, 'It was my Dad who took me when I was a kid. We still go together and have our season-tickets next to each other'. Similarly, Wes, a lifelong Sheffield United fan, said, 'My grandparents got me into football...I used to go to 
home games with them and my uncles'. And Leon, a Tottenham Hotspur fan who also follows the England national team abroad, said, 'It's always been a family thing. I used to go with my parents and sister. Now it's just my Dad and sister. But we always go together'.

Other participants spoke of being introduced to football by family, but, for various reasons, normally attend matches with friends. Bradley, a Watford fan, said, 'I used to go with my Dad and brother every week, but now it varies depending on the game. I have friends that I like to go with, too'. And Fabio, a Norwich City season-ticketholder, said, 'It was my parents who first introduced me to football, but they don't go anymore... I normally go now with friends, as we've got season-tickets together that are shared between us'. For both sets of participants, then, football fandom was a shared experience and rooted in notions of family and friendship.

In addition to their route into fandom, these fans' passionate declarations of love and support for their respective clubs, combined with their regular attendance at home and away matches, means they can be classified as what Giulianotti (2002) might call 'supporters' or 'fans' - evidenced through their 'traditional' and 'hot' fandom. This was also evident through their contemporary expression of fandom. Indeed, all but five participants saw themselves representing 'hardcore' levels of fandom. On a match-day in particular, this was evident through multiple factors, such as their enthusiastic support, choice of location inside stadia (particularly for 'away' games, where fans are often able to choose a specific location inside a small section of the stadium) and vocal encouragement towards their team (normally) during the match. And consistent with previous research which identifies the pub as a central site for the consumption of football (Weed, 2007), almost two-thirds of fans frequented this space before and after matches.

\section{LGBT Fan Groups, Community and Belonging}


LGBT fans' presence has been made increasingly visible by the effect of LGBT Fan Groups. LGBT support groups can play an important role in effecting progressive social change (Formby, 2017), yet they are often only seen as a source of protection or combatting homophobia. The emergence of these groups has challenged football's hypermasculine environment, as well as providing an opportunity for sexual minority fans to network and find a sense of belonging in an environment from which they have traditionally been excluded. At the time of writing, just under half of EPL and EFL clubs have an LGBT Fan Group. This research included seven participants who were founders or co-founders of these groups. They reported various motivations for establishing these groups.

Troy, a lifelong fan of his club and co-founder of its LGBT Fan Group, said, 'For us, it was about raising awareness. There are other LGBT people who go to football, so it was about creating something inclusive'. Similarly, Anton, one of the initial founders of his club's group, said, '[Name of club] is my life...I wanted to make sure the club was a comfortable space and also that LGBT supporters knew there were others like them'. And Christian, cofounder of his club's group, said, 'It's about letting others know that you can be gay and watch football and that football is a safe space for us all'.

Other founders (and co-founders) outlined other motivations for establishing these groups. Mason, a lifelong fan of his club who attends almost every match, said, 'It's about making a difference and standing up for what we believe in'. Spencer, one of numerous cofounders of his club's group, said, 'We hold a lot of social events that allow LGBT fans to meet up and get to know each other'. Finally, for Seth, the motivation for establishing a group was especially important: 'It's important for us because we're subjected to more homophobia than other teams...It was partly about standing up and saying that we're not going to put up with it'. Motivating factors for the establishment of LGBT fan groups are numerous and also align with these gay fans' experiences of football fandom. 
Of the 35 fans interviewed for this research, approximately two-thirds (23) were members of an LGBT fan group aligned to their club. For these fans, the ability to develop a safe community and a sense of belonging with the potential to effect social change on English football was also acknowledged. Evidencing this, Martin, a Crystal Palace fan, said, 'When I came back, I went to matches on my own. Since I became a member, I've found like-minded people to go with'. Gordon said, 'The group is so active, and it gives a great opportunity to socialise with others'. For Noel, Pride of Irons gave him 'a sense of belonging' and an opportunity to 'discuss matches with like-minded fans'. Accordingly, LGBT Fan Groups give these fans space to develop practices of belonging that heterosexual men might do in pubs prior to a match (e.g., Magrath, 2018) or through general supporters' clubs, which have associations with the homophobic ethos of prior generations.

For around half of the fans in this research, the increased visibility of LGBT involvement in English football was the most important outcome of fan groups. Liam, a lifelong Leeds United fan, said, 'Increasing visibility for LGBT communities is so important in football. The group does a great job in publicising itself'. Similarly, Leon said, 'The groups make people more aware of LGBT [involvement] in football. It doesn't matter who or what you are, we all support the same team'. For some fans, including Nick, a Newcastle United fan, and Jason, the increased visibility of LGBT fan groups at matches was an essential factor in why they - and some of their friends - attended matches on a more regular basis. And Warren, a West Bromwich Albion fan, provided some examples of how Proud Baggies had been so prominent: 'They've been on the pitch a few times with a rainbow flag, sometimes the corner flags have rainbows on, too. The club itself also get messages out on social media, which just shows how much they are concerned with diversity'. Increased visibility, then, was central to the importance of LGBT Fan Groups as it connected with 
notions of representation and inclusion, and signified a welcoming environment where fans could belong.

The remaining 12 participants were not members of an LGBT fan group. For some of these men, this was simply due to a lack of time, either due to family or work commitments, or because their club does not have an official group. Interestingly, however, six of these men believed that LGBT fan groups were unnecessary given the inclusive and 'sanitised' nature of English football (Cleland and Cashmore, 2016). Isaac, a Manchester City fan and journalist, said, 'I don’t really see any homophobia at matches, so I just don't think it would be necessary to "other" ourselves like that'. Similarly, Wes said, 'I know we [the club] have got a group, it's just not something I think we need...Football is football and the game has changed'. Finally, Lionel, a Burnley fan, said, 'I guess they're a good thing if you're worried, but I'm not, really. It's not something that the club have had an issue with'. Thus, the sense of community and belonging brought by LGBT Fan Groups was not experienced by these fans.

\section{Gay Male Fans' Experiences}

\section{Cautious Cultural Perceptions}

Despite the increased visibility of LGBT fans in English football, two-thirds of the gay male fans in this research believed that the hypermasculine and heteronormative culture made it an ‘unwelcoming' environment. For example, Wilson, a Reading fan, said, 'Football's still a really masculine environment...It's not exactly welcoming'. Similarly, Grant, a Crawley Town fan now living in Lewes, said, 'There are certain thuggish elements still attached to football and it gives it a dangerous feel, at times'. Wes discussed football's image as 'still being associated with a certain type of fan', while Seth said, 'We [LGBT fans] are still a minority... The vast majority of fans are straight, and we remain an isolated pocket'. For five 
fans, this hypermasculine environment resulted in an expectation of homophobia - even if it rarely materialised - which they believed was a deterrent for more LGBT fans attending matches.

This culture was especially evident in matches involving local rivalries - referred to in English football as a 'derby' match - which these fans believed facilitated a more intimidating and potentially divisive atmosphere when compared to a regular fixture (Magrath, 2018). Tottenham Hotspur fans Gordon and Frazer both made reference to their club's rivalries with Arsenal and Chelsea, while Adie, a lifelong Newcastle United fan, made reference to his club's rivalry with Sunderland. These environments were a primary reason why fans elected to apply 'common sense' as much as possible. This was best evidenced by Leon, for example, who said, 'I certainly wouldn't wear my Spurs rainbow shirt to a derby match. I think it'd just be asking for trouble'.

It was also this environment which led to significant modifications to these fans' behaviours. Indeed, while all but three fans in this research said that they would attend a match with a partner - and many frequently do - 11 also said that they would alter their behaviour to avoid suspicion from other fans. Leon, for example, said, 'We'd have to be careful...My fear would be other people saying things about us, and maybe getting abuse'. Seth said, 'We wouldn't show any signs of affection...A friend and I were mistaken for a couple and we got a few funny looks'. Finally, Liam spoke of the importance of developing 'thick skin' and 'acting more masculine' when attending the match with a partner. These findings are therefore consistent with existing research on how gay men eschew public displays of affection in order to avoid gay stereotypes (see Dean et al., 2014), and conform to football's hypermasculine environment (King, 1997).

\section{Positive Social Experiences}


While there were perceptions that English football was an unwelcoming environment for LGBT fans, all but four of the gay male fans interviewed for this research believed that it had become accepting of homosexuality (e.g., Cashmore and Cleland, 2012; Cleland, 2015; Cleland et al., 2018; Magrath, 2017, 2018). This was particularly evident among the older fans in the sample. Adie said, 'I've noticed a big change in recent years. I think it's really noticeable nowadays'. Similarly, Frazer, a retired author and lifelong Tottenham Hotspur fan, said, 'Attitudes among fans have improved with almost everything...Fans are more welcoming now than they've ever been before'. And for Spencer, 'Racism is what you hear more of...Homophobia has declined massively nowadays'. Many of the younger fans also agreed with these sentiments and, perhaps unsurprisingly, the six fans who believed that homophobia in football was insignificant came from the youngest cohorts (18-24 and 25-35). This was best summarised by David, a Huddersfield Town fan, who said, 'I don't think homophobia is a big issue... The acceptance is just there'.

Evidencing this acceptance, participants also spoke about their routine inclusion in footballing culture. Joshua, for example, a Wolverhampton Wanderers (Wolves) seasonticketholder, said, 'Where I sit in the stadium, it's been the same people for years. They know I'm gay and everyone around me congratulated me on my wedding recently'. Similarly, Grant said, 'Everyone at the club bar that we go to knows I'm gay, and I've never had any problems at all'. Christian and Anton - both of whom were founders of their club's respective LGBT Fan Group - said that they had booked various social events at local pubs near their respective club's stadium. Neither could recall any negative encounters from other fans in the pub. Through these examples, gay male football fans, it could be argued, are afforded a sense of belonging and community into football fandom.

These narratives of English football's improved cultural context are further supported by the declining prevalence of homophobic chanting (c.f. Goldring, 2018). According to all 
but four of these participants, homophobic chanting has considerably declined in recent years - and has become an infrequent phenomenon in English football stadia. For example, Elliott said, 'There used to be homophobic chants - and all sorts of discriminatory chants regularly, but it rarely happens anymore'. Bradley said, 'Homophobic chanting is getting better. I've been following the club a long time and I would say it was actually a lot worse in the 1990s when we were in a lower league'. Eight participants - albeit those from the two youngest cohorts - even said that they had never witnessed any form of homophobic chanting at matches whatsoever. Accordingly, the findings presented in this section provide a challenge to commonly held assumptions that English football lags behind other sports in terms of its acceptance of homosexuality (Stonewall, 2016).

Despite this, however, around half of the participants in this study warned that the level of inclusivity is dependent on the context. Trevor, a Peterborough United fan, said, 'I think it's dependent on where you sit...I've found that some grounds and clubs are better than others'. Similarly, Nick said, 'Football's generally safe now, but so much of that is dependent on which team you support, which matches you go to [and] whether you're at "home" or "away". Supporting this perspective, Simon, an Arsenal season-ticketholder, said, 'It depends on where you sit in the ground... Some places are more boisterous than others, particularly when it comes to chanting'.

Further evidence of the English football's inclusive environment was shown by the fact that 26 of the 35 participants involved in this research said that they felt 'safe' attending matches. For instance, Robbie, a retired Nottingham Forest fan, said, 'Football is more accepting now than ever before... When I was in my twenties, I felt anxious about going to football, but I just don't have that anymore'. Likewise, Mason said, 'When I first started going, I felt intimidated...But now I've been going for years, and feel completely safe, even if the atmosphere isn't as friendly as I'd like'. And, finally, Martin said, 'I still feel wary at 
matches, but I feel so much safer now than I ever did in the past'. Accordingly, these findings counter perceptions that sporting environments remain unsafe for LGBT fans (Stonewall, 2016).

\section{Discussion}

This research has drawn on interviews with 35 gay male fans to explore their experiences of contemporary English football. Adopting an inductive analytic approach, this research presents a range of findings. First, I document the 'authenticity' of these gay male fans (c.f. King, 1997; Pearson, 2012): football was a central component of their lives, and they all spoke passionately about their respective club. This is evidence that existing attempts to conceptualise football fandom should be extended beyond English football's traditional demographic. While LGBT fans have traditionally existed only on the periphery of football fandom, their increased visibility in recent years confirms that this is no longer the case. These findings also demonstrate that LGBT fans' consumption of football is not relegated to what Giulianotti (2002) calls 'cool'; neither should they be treated simply as 'followers'. Indeed, as this research shows, LGBT fans frequently are 'traditional' and 'hot' football fans, thus diversifying English football's traditionally narrow vision of masculinity. Accordingly, their experiences must be treated as comparably authentic with any other type of fan.

This research also focused on the recent emergence of LGBT Fan Groups. Approximately, two-thirds of participants were, in some way, involved in these organisations. Motivating factors for establishing or participating in these groups were numerous and can be loosely categorised into three areas: (1) awareness and visibility of LGBT fandom; (2) safety and inclusion for LGBT fans attending football; (3) socialising and networking with other LGBT fans. Accordingly, LGBT Fan Groups must be recognised as safe and valuable spaces for sexual minority fans in a broader environment traditionally hostile to their presence. 
These spaces are important because they can provide the environment to foster interaction and engagement with different people.

Much like other sport and leisure sites (e.g. Neal et al., 2019), LGBT Fan Groups also provide gay male fans with an increased sense of community and belonging. Indeed, similar to participants in Jackson's (2020) study of a London bowling alley, this feeling was especially important for those who have previously encountered hostility and discrimination because of their ethnicity, sexual orientation and so on. Furthermore, particular spaces and groups have been shown to help foster friendships across diverse groups (Vincent et al., 2018), suggesting that LGBT Fan Groups may be important sites for facilitating crosssexuality networks and friendships at sporting events.

While LGBT Fan Groups had effected some form of social change to English football, two-thirds of participants interviewed felt that English football stadia remain overwhelmingly heteronormative environments. To this end, the culture associated with English football partly led to strategic hiding of gay identities. Indeed, while all but three participants felt confident in attending matches with a partner - and many frequently do almost a third avoid public displays of affection (Dean et al., 2014) in order to better conform to football's hypermasculine environment (King, 1997). This was especially common at matches involving rival clubs, where discriminatory behaviour - such as homosexuallythemed chanting - was often more intense (Magrath, 2018).

Despite these fans' ongoing concerns, all but four acknowledged that English football had become increasingly acceptant of homosexuality in recent years (Cashmore and Cleland, 2012; Cleland, 2015; Cleland et al., 2018; Magrath, 2017, 2018). Notably, 26 of the 35 participants said that they felt 'safe' attending matches, and that previous feelings of intimidation and anxiety - particularly among participants in the older cohorts - had dissipated in recent years. Moreover, contrary to some advocacy reports which claim 
homophobic chanting remains an endemic issue inside English football stadia (Goldring, 2018; Stonewall, 2016), gay male fans in this research believed that this had considerably declined in recent years (see Magrath, 2018). Eight participants, all from the youngest two age cohorts, even said that they had never witnessed any homophobic chanting. The decline of explicit anti-social behaviour such as homophobic chanting also supports Cleland and Cashmore's (2016) argument that English football - particularly in the EPL - is becoming an increasingly sanitised environment.

While this research is a valuable addition to existing work, there are some limitations. First, LGBT people are not a homogenous group, and this research focuses only on gay male football fans. Because of broader challenges which they may face, lesbian, bisexual and/or transgender fans' experiences may be more complex; further research is therefore required. Moreover, in the sample of 35 gay male football fans, all but one identified as White British. Thus, although English stadia 'remain overwhelmingly white male spaces' (Lawrence and Davis, 2018: 703), BAME fans still comprise a minority of fans inside stadia. Of course, this recruitment challenge may speak to the fact that BAME people may receive elevated levels of stigma, and may be unwilling to discuss these experiences. Nevertheless, their voices must be heard in future research. Other limitations of this research include the potentially problematic 'digital divide' of recruiting participants through the internet (Sparkes and Smith, 2014: 114), especially as this study used social media to recruit its participants. Finally, only $25 \%$ of English professional football clubs were represented in this research. These clubs covered most of the main areas of England. However, it is important to acknowledge context here, particularly as issues of homophobia can be influenced by geographical location.

This study highlights several important avenues for future research. While LGBT Fan Groups in English football have increased over the past decade, comparable visibility and 
community is not evident in other sports. How gay men's consumption of sport fits with other changes to their lives is an important area of further study, as well as how these experiences fit with changing patterns of football consumption more broadly. Furthermore, while English football has made significant advances towards the inclusion of sexual minorities, there are broader challenges for the football industry internationally, where explicit support for the LGBT community is significantly weaker in many countries (see Smith et al., 2014). Thus, future research examining LGBT fans' experiences internationally - both in football and other sports - is warranted.

In conclusion, this research is a valuable addition to existing work on fandom. It is the first research to focus explicitly on the stadium climate for gay male football fans. In doing so, it advances our cultural understandings of the growing acceptance of the LGBT community's place in a traditionally hypermasculine British space. It also documents the importance of community (Neal et al., 2019) in providing LGBT fans with a safe space facilitating greater levels of inclusivity in sport. It also helps us to better understand the behaviour of gay male fans in this environment. This research should therefore be treated as a point of departure for further providing LGBT fans with a voice where they have previously been under-represented and unheard. 


\section{Funding information}

This research was funded by the American Institute of Bisexuality (AIB).

\section{References}

Anderson E, Magrath R and Bullingham R (2016) Out in sport. London: Routledge.

Braun V, Clarke V and Weate P (2016) Using thematic analysis in sport and exercise research. In: Smith B and Sparkes AC (eds) Routledge handbook of qualitative research in sport and exercise. London: Routledge, 191-205.

Cashmore E, and Cleland J (2012) Fans, homophobia and masculinities in association football. British Journal of Sociology 63(2): 370-387.

Charmaz K (2014) Constructing grounded theory. London: Sage.

Cleland J (2014) Association football and the representation of homosexuality by the print media. Journal of Homosexuality 61(9): 1269-1287.

Cleland J (2015) Discussing homosexuality on association football fan message boards. International Review for the Sociology of Sport 50(2): 125-140.

Cleland J and Cashmore E (2016) Football fans' views of violence in British football. Journal of Sport and Social Issues 40(2): 124-142.

Cleland J, Magrath R and Kian EM (2018) The internet as a site of decreasing cultural homophobia in association football. Men and Masculinities 21(1): 91-111.

Cleland J, Kilvington D and Dixon K (2020) Online research methods in sports studies. London: Routledge.

Crawford G (2004) Consuming sport. London: Routledge.

Curry TJ (1991) Fraternal bonding in the locker room. Sociology of Sport Journal 8(2): 119135. 
David M and Millward P (2012) Football's coming home? British Journal of Sociology 63(2): 349-369.

Dean L, Loehr A and Miller LR (2004) Formal rights and informal privileges for same-sex couples. American Sociological Review 79(6): 1172-1195.

Elling A, De Knop P and Knoppers A (2003) Gay/lesbian sports clubs and events. International Review for the Sociology of Sport 38(4): 441-456.

Formby E (2017) Exploring LGBT spaces and communities. London: Routledge.

García B, de Wolff M, Welford J and Smith B (2016) Facilitating inclusivity and broadening understandings of access at football clubs. European Sport Management Quarterly 17(2): 226-243.

Gaston L, Magrath R and Anderson E (2018) From hegemonic to inclusive masculinities in English professional football. Journal of Gender Studies 27(3): 301-312.

Gelinas L, Pierce R, Winkler S, Glenn Cohen I, Fernandez Lynch H and Bierer BE (2017) Using social media as a research recruitment tool. American Journal of Bioethics 17(3): 3-14.

Giulianotti R (2002) Supporters, followers, fans, and flaneurs. Journal of Sport and Social Issues 26(1): 25-46.

Goldblatt D (2014) The game of our lives. London: Penguin.

Goldring J (2018) LGBT end-of-season survey. London: Football v. Homophobia.

Hekma G (1998) 'As long as they don't make an issue of it'. Journal of Homosexuality 35(1): $1-23$.

Jackson E (2020) Bowling together? Sociology 54(3): 518-533.

Jensen J (1992) Fandom as pathology. In: Lewis L (ed.) The adoring audience. London: Routledge, 9-29.

Jones KW (2008) Female fandom. Sociology of Sport Journal 25(4): 516-537. 
King A (1997) The lads. Sociology 31(2): 329-346.

King A (2002) The end of the terraces. London: Bloomsbury.

Kossakowski R (2017) Where are the hooligans? International Review for the Sociology of Sport 52(6): 693-711.

Lawrence S and Davis C (2018) Fans for diversity? International Journal of Sport Policy and Politics 11(4): 701-713.

Leonard JM (2005) The geography of visitor attendance at college football games. Journal of Sport and Behavior 28(3): 231-252.

Magrath R (2017) Inclusive masculinities in contemporary football. London: Routledge.

Magrath R (2018) 'To try and gain an advantage for my team'. Sociology 52(4): 709-726.

McCormack, M. (2012) The declining significance of homophobia. New York, NY: Oxford University Press.

McCormack M and Anderson E (2014) The influence of declining homophobia on men's gender in the United States. Sex Roles 71(3-4): 109-120.

Mehra B, Merkel C and Peterson Bishop A (2004) The internet for empowerment of minority and marginalised users. New Media and Society 6(6): 781-802.

Millward P (2011) The global football league. Basingstoke: Palgrave.

Neal S, Bennett K, Cochrane A and Mohan G (2019) Community and conviviality? Sociology 53(1): 69-86.

Pearson G (2012) An ethnography of English football fans. Manchester: University of Manchester Press.

Pfister G and Pope S (2018) Female football players and fans. Basingstoke: Palgrave. Pope S (2017) The feminization of sports fandom. London: Routledge.

Poynter R (2010) The handbook of online and social media research. Chichester: Wiley. Pride in Football (2020) Pride in football. Available at: https://www.prideinfootball.co.uk 
Pronger B (1990) The arena of masculinity. New York: St Martin's.

Putnam R (2000) Bowling alone: The collapse and revival of American community. New York: Simon Schuster.

Raphael R (1988) The men from the boys. Lincoln, NE: University of Nebraska Press.

Riess SA (1995) Sport in industrial America, 1850-1920. Wheeling, IL: Harlan Davidson.

Smith TW, Son J and Kim J (2014) Public attitudes towards homosexuality and gay rights across time and countries. Chicago: NORC.

Sparkes A and Smith B (2014) Qualitative research methods in sport, exercise and health. London: Routledge.

Stonewall (2016) Homophobic views still prevalent in sport. Available at:

https://www.stonewall.org.uk/media-centre/media-release/homophobic-views-sport

Taylor M (2008) The association game. Harlow: Pearson.

Vincent C, Neal S and Iqbal H (2018) Friendship and diversity. Basingstoke: Palgrave.

Watt L and Elliot M (2019) Homonegativity in Britain. Journal of Sex Research 56(9): 11011114.

Weed M (2007) The pub as a virtual football fandom venue. Soccer and Society 8(2/3): 399414.

Rory Magrath is author of Inclusive Masculinities in Contemporary Football (Routledge, 2017) and co-author of Out in Sport: The Experiences of Openly Gay and Lesbian Athletes in Competitive Sport (Routledge, 2016). He is currently Associate Professor of Equality and Diversity at Solent University, Southampton. His research focuses on declining homophobia and the changing nature of masculinities, particularly in the context of sport. He frequently tweets about his research: @RoryMagrath

\footnotetext{
' This research is part of a broader project which explores the experiences of LGBT football fans. More information is provided about this in the Methods section of this article.
} 
ii It is in this space where most LGBT Fan Groups have their most active social media accounts. An up-to-date list of these clubs and their Twitter presence can be located here:

https://prideinfootball.co.uk/index.php/members/

iii The second 'wave' included the relaxing of fans with season-tickets to those who attend five or more matches per season. 